\title{
Inactivation of medial prefrontal cortex or acute stress impairs odor span in rats
}

\author{
Don A. Davies, ${ }^{1,2}$ Joel J. Molder, ${ }^{1,2}$ Quentin Greba, ${ }^{1}$ and John G. Howland ${ }^{1,3}$ \\ ${ }^{1}$ Department of Physiology, University of Saskatchewan, Saskatoon, Saskatchewan, Canada S7N 5E5
}

\begin{abstract}
The capacity of working memory is limited and is altered in brain disorders including schizophrenia. In rodent working memory tasks, capacity is typically not measured (at least not explicitly). One task that does measure working memory capacity is the odor span task (OST) developed by Dudchenko and colleagues. In separate experiments, the effects of medial prefrontal cortex (mPFC) inactivation or acute stress on the OST were assessed in rats. Inactivation of the mPFC profoundly impaired odor span without affecting olfactory sensitivity. Acute stress also significantly reduced odor span. These findings support a potential role of the OST in developing novel therapeutics for disorders characterized by impaired working memory capacity.
\end{abstract}

Working memory, a type of short-term memory for storage and manipulation of information necessary for higher order cognition (Goldman-Rakic 1996; Baddeley 2003; D'Esposito 2007), is impaired in numerous brain-related disorders including schizophrenia (Barch et al. 2009). Thus, preclinical research using the appropriate tasks to measure working memory in rodents may lead to improved therapeutics for these disorders (Dudchenko et al. 2012). In the case of schizophrenia, working memory capacity is decreased (Chey et al. 2002; Gold et al. 2010) and the Cognitive Neuroscience Treatment Research to Improve Cognition in Schizophrenia (CNTRICS) group has identified capacity as a component of working memory requiring more basic research before being included in the translational battery (Barch and Smith 2008; Dudchenko et al. 2012).

In rodents, span tasks (Dudchenko et al. 2000; Young et al. 2007; Cui et al. 2011) are argued to offer the best potential for measuring working memory capacity in translational models of schizophrenia (Dudchenko et al. 2012). In rats, odor span tasks (OST) involve a modified serial delayed nonmatch to sample procedure to receive food reward by either digging in small bowls filled with scented sand (Fig. 1A; Dudchenko et al. 2000; Rushforth et al. 2010, 2011) or displacing scented lids on bowls (MacQueen et al. 2011; Galizio et al. 2013). Bowls are added one at a time during a "span" and the novel bowl must be chosen for a reward to be received. Systemically administered nicotinic receptor agonists increase odor span (Rushforth et al. 2010) while the NMDA receptor antagonist dizocilpine (MK-801) and GABA-A modulator chlordiazepoxide selectively impair performance of the OST (MacQueen et al. 2011; Galizio et al. 2013). Rats that were administered a subchronic regime of ketamine, to model schizophrenia symptoms, are also impaired on the OST, an effect prevented by nicotine (Rushforth et al. 2011).

Research regarding the neural substrates involved in the OST is scarce. Previous research indicates that the OST does not depend on the hippocampus, although a variant involving spatial cues does (Dudchenko et al. 2000). As some researchers have speculated that the OST depends on the prefrontal cortex (PFC) (Dudchenko et al. 2012), the first goal of the present study was to assess the role

\footnotetext{
${ }^{2}$ These authors contributed equally to this work.

${ }^{3}$ Corresponding author

E-mail john.howland@usask.ca

Article is online at http://www.learnmem.org/cgi/doi/10.1101/lm.032243.113.
}

of the PFC in the OST in rats. The medial PFC (mPFC) is involved in working memory in rodents (Kolb 1990; Seamans et al. 1995; Floresco et al. 1997; Aujla and Beninger 2001; Holmes and Wellman 2009), although the tasks used in these experiments do not directly measure working memory capacity (Dudchenko 2004; Dudchenko et al. 2012). In humans, the role of the PFC in span tasks is controversial (D'Esposito and Postle 1999; Bor et al. 2006). Given these findings, we assessed the effect of temporary inactivation of the MPFC (McFarland and Kalivas 2001; St. Onge and Floresco 2010) on the OST in male rats. We also conducted a test of odor sensitivity (Witt et al. 2009; Malkova et al. 2012) following inactivation of the MPFC as odor sensitive neurons are found in the prelimbic and infralimbic subregions (Nikaido and Nakashima 2011). In rodents, acute stress impairs working memory likely via alterations in mPFC function (Diamond et al. 1996; Arnsten 2009; Holmes and Wellman 2009; Butts et al. 2011; Devilbiss et al. 2012). To date, studies have not assessed the effects of acute stress on working memory capacity per se, as measured by the OST. Therefore, the second objective of the present experiments was to test the effects of acute restraint stress (MacDougall and Howland 2012) on the OST.

Three separate groups of adult male Long-Evans rats (220380 g; Charles River, Quebec) were used. Rats were pair housed in a colony room with a 12-h light-dark cycle (lights on at 07:00) with ad libitum access to food and water for $1 \mathrm{wk}$. Rats in the OST experiments were subsequently individually housed and food restricted to maintain $85 \%$ of their free feeding weight. The experimenter testing the rats was blind to the treatment status of the rats. Rats in the OST and odor sensitivity experiments had cannulae implanted bilaterally in $\mathrm{mPFC}(\mathrm{AP}+2.60 \mathrm{~mm}$, ML $\pm 0.70 \mathrm{~mm}, \mathrm{DV}-3.60 \mathrm{~mm}$, flat skull) using standard procedures (Cazakoff and Howland 2011) and were permitted at least $7 \mathrm{~d}$ to recover. Rats were handled for $3 \mathrm{~d}$ before testing. Placements of the infusion needles were obtained postmortem using conventional methods (Cazakoff and Howland 2011) with the aid of a rat brain atlas (Paxinos and Watson 1997). All experiments were conducted in accordance with the standards of the Canadian

(C) 2013 Davies et al. This article is distributed exclusively by Cold Spring Harbor Laboratory Press for the first 12 months after the full-issue publication date (see http://learnmem.cshlp.org/site/misc/terms.xhtml). After 12 months, it is available under a Creative Commons License (Attribution-NonCommercial 3.0 Unported), as described at http://creativecommons.org/licenses/by-nc/3.0/. 


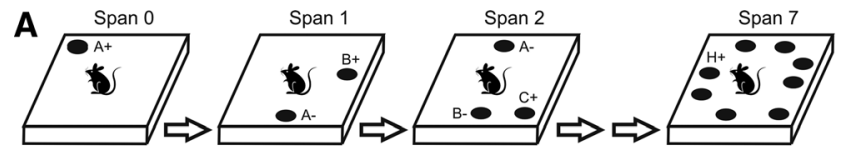

B

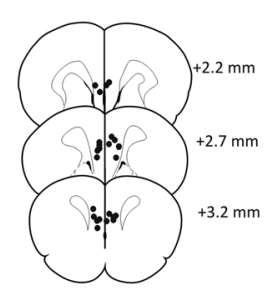

C

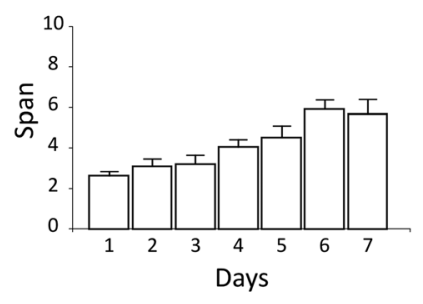

D

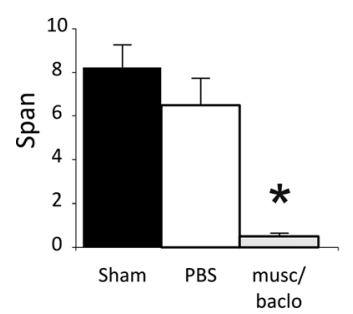

E

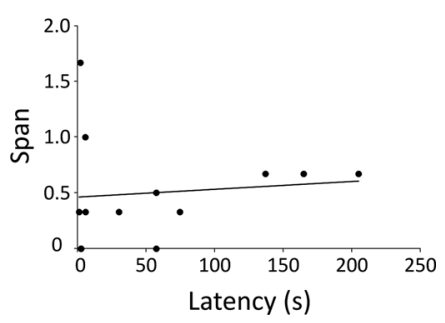

Figure 1. Effects of medial prefrontal cortex (mPFC) inactivation on odor span capacity in rats. $(A)$ Schematic of the apparatus and procedure for the odor span task (see text for details; schematic based on Dudchenko et al. 2000, 2012). Odors are denoted with letters. On subsequent trials, the bowl (black circle) containing novel odor is rewarded $(+)$ while the other stimuli are not rewarded $(-)$. Rats are tested on a series of trials until an error is made. The number of bowls on the platform when an error is made minus one is recorded as the span. Note that a given odor is moved to a different position on the platform for each trial so that spatial cues cannot be used to solve the task. (B) Placements (black dots) of the infusion needle tips for rats in the MPFC inactivation and odor span experiment $(n=13)$. Infusion sites were located in both the prelimbic and infralimbic areas of the mPFC and impinged on the dorsal peduncular cortex in four subjects. The distance each plate is anterior to bregma is indicated in millimeters. (C) Mean (+ standard error of the mean) odor spans during the $7 \mathrm{~d}$ of training immediately prior to testing for rats in the MPFC inactivation experiment. $(D)$ Mean spans for the rats following each treatment of the mPFC inactivation experiment. Musc/baclo refers to the muscimol/baclofen treatment to temporarily inactivate the mPFC. (E) Correlation between spans and latencies to the first choice in the olfactory span task for rats treated with muscimol/baclofen. $(*)$ Indicates a significant difference from all other groups $(P<0.05)$.

Council on Animal Care and were approved by the University of Saskatchewan Animal Research Ethics Board.

Methods for the OST (Fig. 1A) closely followed those described by Dudchenko et al. (2000). A black corrugated plastic platform $\left(91.5 \mathrm{~cm}^{2}, 2.5-\mathrm{cm}\right.$ border, $95 \mathrm{~cm}$ above the floor) surrounded by an off-white curtain was used. Odors ( $0.5 \mathrm{~g}$ of dried spice; allspice, anise seed, basil, caraway, celery seed, cinnamon, cloves [0.1 g], cocoa, coffee, cumin, dill, fennel seed, garlic, ginger, lemon and herb, marjoram, mustard powder, nutmeg, onion powder, orange, oregano, paprika, sage, and thyme) were mixed in Premium Play Sand (100 g; Quikrete Cement Products) and placed in white porcelain bowls $(4.5 \mathrm{~cm}$ in height, $9 \mathrm{~cm}$ in diameter). The bowls were randomly placed in one of 24 equally spaced locations along the perimeter of the platform marked with Velcro.

Initially, rats were shaped to dig for a cereal reward (Kellogg's Froot Loops) in a bowl filled with $100 \mathrm{~g}$ of unscented sand. Rats were trained until they would reliably dig for the reward regardless of bowl placement on the platform $(\sim 1 \mathrm{wk})$. Rats were then trained on the nonmatching to sample task (NMS). In the sample phase of a trial, the subject was presented with a bowl of scented sand randomly located on the platform. After the subject dug and retrieved the reward, it was removed from the platform and placed behind the curtain. The experimenter then moved the bowl to the opposite side of the platform and added a second bowl with a different odor to the platform that contained a reward. In the choice phase, the subject was placed on the platform opposite both bowls and allowed to freely sample them. A choice was scored when the subject dug or placed its paws or nose on the sand. An error was scored if the rats chose the previous odor. The subjects were given six NMS trials daily until the novel odor was selected on five of the six trials for $3 \mathrm{~d}$. Subsequently, rats were trained on the OST. Trials were run as described for the NMS task except that bowls containing novel odors (for that trial) were added until the rat made an error (i.e., dug in any of the bowls except the new one). The previously presented bowls were randomly moved before each novel bowl was added to the platform. The span for a given trial was scored as the number of odor bowls correctly chosen minus one. During training, three or four rats were transported to the testing room together. Each rat performed three spans per day with a break between spans while the other rats were tested. The average of the three spans is reported. Once performance was stable (7-15 d of training), the effects of mPFC inactivation or acute stress on span were assessed using a within subjects design (see below). On test days, rats were tested on three spans consecutively or for $30 \mathrm{~min}$. To confirm that the subjects were using odor to solve the task, two probe sessions were conducted. The first probe session assessed if the scent of the reward guided choice by omitting the reward from all bowls on a trial. When the subject made a correct choice, a food reward was dropped on top of the sand. The second probe tested if the subjects marked the bowls when they sampled them by replacing all the bowls with new ones containing new, scented sand. Performance of the rats did not deteriorate during either of these probe sessions (data not shown).

In the mPFC inactivation experiment, rats were tested on the OST 15 min following three treatments in a counterbalanced order: sham infusions, PBS infusions, and mPFC inactivation using a combination of the GABA receptor agonists muscimol (Sigma-Aldrich Canada) and baclofen (Sigma-Aldrich Canada) (McFarland and Kalivas 2001; St. Onge and Floresco 2010). The drugs were dissolved separately in PBS (500 ng/ $\mu \mathrm{L})$ and mixed together. Rats were habituated to the infusion process as described previously (Cazakoff and Howland 2011) and trained for at least $2 \mathrm{~d}$ between treatments. Infusions $(0.5 \mu \mathrm{L}$ in $1 \mathrm{~min}$ via a PHD 2000 infusion pump, Harvard Apparatus) were performed by inserting custom-made needles (30-gauge stainless steel tubing and PE-50 tubing) $1 \mathrm{~mm}$ past the end of the cannulae. In the sham condition, shorter needles were used that did not exit the cannulae and no solution was delivered. The infusion needles were left in position for an additional minute after the infusion to allow for diffusion.

Figure 1B shows the infusion sites of the rats in the mPFC lesion and OST experiment. Figure 1C displays the average span for the $7 \mathrm{~d}$ immediately before the first infusions. A relatively stable span of about seven odors was achieved, as reported previously (Dudchenko et al. 2000; Rushforth et al. 2010, 2011). Figure 1D shows the effects of sham, PBS, or muscimol/baclofen infusions on odor span. A dramatic and significant reduction in span was observed in rats following muscimol/baclofen infusions into the mPFC compared to the other treatments. A repeated measures ANOVA reveals a significant main effect of treatment $\left(F_{(2,24)}=\right.$ 24.32, $P<0.001$ ); post-hoc analyses (Newman-Keuls) indicated that the muscimol/baclofen treatment resulted in significantly lower spans than the other two groups $(P<0.05)$. The day after 
A
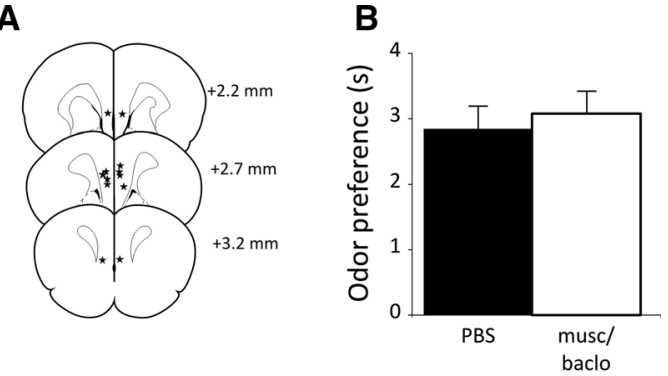

C

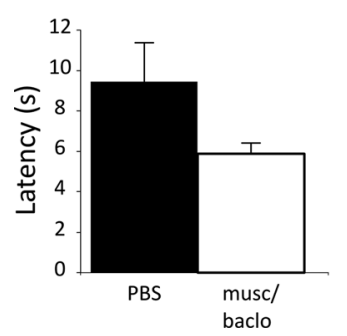

Figure 2. Effects of medial prefrontal cortex (mPFC) inactivation on olfactory sensitivity in rats. (A) Placements (black stars) of the infusion needle tips for rats in the medial prefrontal cortex (mPFC) inactivation and olfactory sensitivity experiment $(n=6)$. The distance each plate is anterior to bregma is indicated in millimeters. $(B)$ Mean (+ standard error of the mean) preference for the scented bowl compared to the unscented bowl. Musc/baclo refers to the muscimol/baclofen treatment to temporarily inactivate the mPFC. (C) Mean latency for the rats to explore the first bowl according to treatment.

treatment, spans recovered in all rats (mean span, $8.00 \pm 1.4$ ). The latency for subjects to dig in the first bowl was greater for rats following mPFC inactivation $(57.31 \pm 21.0 \mathrm{sec})$ than the other two treatments (sham, $2.88 \pm 0.6 \mathrm{sec}$; PBS, $1.92 \pm 0.2 \mathrm{sec}, F_{(2,24)}=$ 8.11, $P=0.002$; Newman-Keuls post hoc, $P<0.05)$. Inspection of the latency data following mPFC inactivation (Fig. 1E) revealed a bimodal distribution, with some rats $(n=6)$ displaying long latencies ( $>50 \mathrm{sec}$ ) and others $(n=7)$ displaying latencies similar to those following sham and PBS treatments. A correlation performed on latency vs. span length revealed no relationship between the latency for rats to make a choice and span length $(r=$ $0.11, P=0.73$ ) (Fig. 1E).

The olfactory sensitivity test was used to detect deterioration of olfactory function following mPFC inactivation (Witt et al. 2009; Malkova et al. 2012). Testing occurred in a 40-cm $\times$ $40-\mathrm{cm} \times 60-\mathrm{cm}$ (height) white corrugated plastic open field. Two bowls containing $100 \mathrm{~g}$ of sand were used for each trial; one was unscented and the other was scented with $0.5 \mathrm{~g}$ of a randomly chosen odor. A separate group of rats $(n=6)$ was infused with either PBS or the GABA agonists and individually placed in the empty open field for $15 \mathrm{~min}$. The bowls were then placed in opposite corners of the box and the behavior of the rats was recorded for $3 \mathrm{~min}$. All rats were tested once in the PBS condition and once in the GABA agonist condition with 1 wk between the two tests (order was counterbalanced). Latency to approach the first bowl and total exploration time of each bowl was scored in a manner similar to object exploration using stopwatches (Cazakoff and Howland 2011).

Figure 2A shows the placements of the infusions for the rats tested in the olfactory sensitivity test. Rats spent significantly more time exploring the scented bowl than the unscented bowl, irrespective of treatment condition (one-sample $t$-test vs. 0 or equal exploration of the bowls; PBS, $t_{(5)}=3.64, P=0.015$; musci$\mathrm{mol} /$ baclofen, $t_{(5)}=3.32, P=0.021$ ) (Fig. $2 \mathrm{~B}$ ). Treatment did not significantly affect the preference of the rats for the scented bowl (paired $t$-test, $t_{(5)}=-0.20, P=0.85$ ). Furthermore, there was no significant difference as a result of treatment in the amount of time spent exploring either the scented bowl ( $\mathrm{PBS}=5.61 \pm 1.0$ sec, muscimol/baclofen $=7.47 \pm 0.9 \mathrm{sec}$ ). In this experiment, $\mathrm{mPFC}$ inactivation had no effect on latency in this test of spontaneous olfactory-related behavior (paired $t$-test, $t_{(5)}=0.68, P=$ 0.53) (Fig. 2C).

The effects of acute stress on the OST were tested in a third experiment. Figure $3 \mathrm{~A}$ shows the mean span of the rats during the $7 \mathrm{~d}$ preceding acute stress. Acute stress was achieved by immobilizing rats in a Plexiglas restraint tube (544-RR, Fisher Scientific) in a brightly lit novel room for $30 \mathrm{~min}$ (MacDougall and Howland 2012). All rats were transported from the room where stress was administered to the room for the OST and span testing began shortly afterward. Acute stress significantly reduced span when compared to either the day prior or the day after stress (repeated measures ANOVA, $F_{(2,12)}=4.44, P=0.036$; Newman-Keuls post hoc, $P<0.05$ ) (Fig. 3B)

The present study yielded a series of novel results. Our first experiment demonstrates that inactivation of the mPFC impairs performance of the OST (Fig. 1). Rats tested in our laboratory displayed similar acquisition rates and mean spans to those in previous reports that have used the version of the OST that requires the rats to dig in sand-filled bowls (Dudchenko et al. 2000; Rushforth et al. 2010, 2011). The involvement of the mPFC has been reported for a variety of working memory tasks (Holmes and Wellman 2009) including delayed alternation (Kolb 1990; Baeg et al. 2003) and the delayed win-shift task on the radial arm maze (Seamans et al. 1995, 1998; Floresco et al. 1997; Aujla and Beninger 2001; Lapish et al. 2008), although these tasks do not specifically measure working memory capacity as the OST does. Working memory capacity is a complex cognitive construct that is incompletely understood (Barch and Smith 2008; Dudchenko et al. 2012) but requires appropriate allocation of attentional resources (Leonard et al. 2013). Rats with mPFC lesions are severely impaired on tasks which measure attention such as the five-choice serial reaction time task (Chudasama and Robbins 2004) raising the possibility that an attentional impairment may underlie the reduction in span capacity observed. However, working memory impairments following mPFC lesions have also been proposed to result from impaired inhibitory response control (Holmes and Wellman 2009).

Inactivation of the mPFC dramatically increased the latency of six out of 13 rats to dig in the first bowl (Fig. 1E). While a nonselective effect of the infusion on brain function may have increased the latency, this is unlikely as latency was unaffected following PBS infusions in the OST or the olfactory sensitivity test following
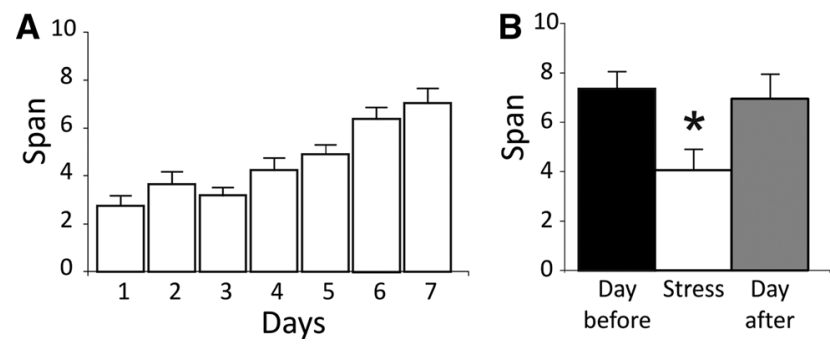

Figure 3. Effects of acute stress on odor span capacity in rats. $(A)$ Mean ( + standard error of the mean) odor spans during the $7 \mathrm{~d}$ of training immediately prior to testing for rats in the acute stress and odor span experiment $(n=7)$. (B) Mean spans for the day before stress, day of stress, and day after stress. $\left(^{*}\right)$ Indicates a significant difference from all other groups $(P<0.05)$. 
infusions of either PBS or the GABA receptor agonists (Fig. 2B). It is worth noting that the rats tested in the OST were subjected to a stereotyped training schedule for days before their infusions while rats in the olfactory sensitivity test were not. In previous reports using other maze tasks that require significant training, mPFC inactivations did not affect response latencies (Floresco et al. 1997), although in operant-based tasks, increases in latencies have been observed (St. Onge and Floresco 2010). Latency was not correlated with performance of the OST (Fig. 1E); thus, it is unlikely that this was a critical determinant of the results obtained. Given that odor sensitive neurons are found in the mPFC (Nikaido and Nakashima 2011), another possible explanation for the dramatically reduced span observed is that rats were anosmic following mPFC inactivations. However, rats with $\mathrm{mPFC}$ inactivations performed normally on the olfactory sensitivity test (Fig. 2B), consistent with results demonstrating that olfactory recognition is intact in mice with lesions of the mPFC (Devito and Eichenbaum 2011).

Immediately following acute restraint stress, performance of the OST was impaired, while $24 \mathrm{~h}$ after stress, mean spans returned to levels similar to those before stress (Fig. 3B). These findings demonstrate that performance of the OST, like other working memory tasks (Diamond et al. 1996; Arnsten and Goldman-Rakic 1998; Butts et al. 2011; Devilbiss et al. 2012), is sensitive to the short-term effects of acute stress. Acute stress causes rapid changes in the physiology of mammals, including the release of catecholamines and glucocorticoid hormones in a timeframe of minutes (Joels and Baram 2009; Koolhaas et al. 2011) that aligns with the behavioral effects observed on the OST. The actions of both catecholamines (particularly dopamine) and glucocorticoids (corticosterone) in the mPFC have been implicated in the disruptive effects of acute stress on working memory (Arnsten 2009; Holmes and Wellman 2009; Butts et al. 2011). Thus, given that mPFC inactivation disrupted performance on the OST, the neural substrates mediating the effects of acute stress on the OST may include the mPFC. These data are consistent with the growing literature showing that acute stress impairs a range of executive functions mediated by the mPFC (Holmes and Wellman 2009; Butts et al. 2013). However, it should be noted that some aspects of executive functioning, such as reversal learning, are facilitated by acute stress (Graybeal et al. 2011; Thai et al. 2013).

The CNTRICS group has identified working memory capacity as a construct requiring more basic research before being included in the translational battery for drug development (Barch and Smith 2008; Dudchenko et al. 2012). The results of the present study contribute to this goal by demonstrating that memory capacity, as measured by the OST in rats, is sensitive to inactivation of the mPFC and the short-term effects of acute stress. Future experiments designed to assess the validity of putative cognitive enhancers for the brain disorders such as schizophrenia (Rushforth et al. 2011) may benefit from including the OST in their test battery (Young et al. 2009; Dudchenko et al. 2012).

\section{Acknowledgments}

This work was supported by a Discovery Grant from the Natural Sciences and Engineering Research Council of Canada to J.G.H. J.G.H. is a National Alliance for Research on Schizophrenia and Depression Young Investigator and a Canadian Institutes of Health Research New Investigator. J.J.M. was supported by a Biomedical Undergraduate Student Scholarship from the College of Medicine, University of Saskatchewan.

\section{References}

Arnsten AF. 2009. Stress signalling pathways that impair prefrontal cortex structure and function. Nat Rev Neurosci 10: 410-422.
Arnsten AF, Goldman-Rakic PS. 1998. Noise stress impairs prefrontal cortical cognitive function in monkeys: Evidence for a hyperdopaminergic mechanism. Arch Gen Psychiatry 55: 362-368.

Aujla H, Beninger RJ. 2001. Hippocampal-prefrontocortical circuits: PKA inhibition in the prefrontal cortex impairs delayed nonmatching in the radial maze in rats. Behav Neurosci 115: 1204-1211.

Baddeley A. 2003. Working memory: Looking back and looking forward. Nat Rev Neurosci 4: 829-839.

Baeg EH, Kim YB, Huh K, Mook-Jung I, Kim HT, Jung MW. 2003. Dynamics of population code for working memory in the prefrontal cortex. Neuron 40: $177-188$.

Barch DM, Smith E. 2008. The cognitive neuroscience of working memory: Relevance to CNTRICS and schizophrenia. Biol Psychiatry 64: $11-17$.

Barch DM, Berman MG, Engle R, Jones JH, Jonides J, Macdonald A III, Nee DE, Redick TS, Sponheim SR. 2009. CNTRICS final task selection: Working memory. Schizophr Bull 35: 136-152.

Bor D, Duncan J, Lee AC, Parr A, Owen AM. 2006. Frontal lobe involvement in spatial span: Converging studies of normal and impaired function. Neuropsychologia 44: 229-237.

Butts KA, Weinberg J, Young AH, Phillips AG. 2011. Glucocorticoid receptors in the prefrontal cortex regulate stress-evoked dopamine efflux and aspects of executive function. Proc Natl Acad Sci 108: $18459-18464$.

Butts KA, Floresco SB, Phillips AG. 2013. Acute stress impairs set-shifting but not reversal learning. Behav Brain Res 252: 222-229.

Cazakoff BN, Howland JG. 2011. AMPA receptor endocytosis in rat perirhinal cortex underlies retrieval of object memory. Learn Mem 18: $688-692$.

Chey J, Lee J, Kim YS, Kwon SM, Shin YM. 2002. Spatial working memory span, delayed response and executive function in schizophrenia. Psychiatry Res 110: 259-271.

Chudasama Y, Robbins TW. 2004. Psychopharmacological approaches to modulating attention in the five-choice serial reaction time task: Implications for schizophrenia. Psychopharmacology (Berl) 174: 86-98.

Cui Y, Jin J, Zhang X, Xu H, Yang L, Du D, Zeng Q, Tsien JZ, Yu H, Cao X. 2011. Forebrain NR2B overexpression facilitating the prefrontal cortex long-term potentiation and enhancing working memory function in mice. PLoS One 6: e20312.

D'Esposito M. 2007. From cognitive to neural models of working memory. Philos Trans R Soc Lond B Biol Sci 362: 761-772.

D’Esposito M, Postle BR. 1999. The dependence of span and delayed-response performance on prefrontal cortex. Neuropsychologia 37: $1303-1315$.

Devilbiss DM, Jenison RL, Berridge CW. 2012. Stress-induced impairment of a working memory task: Role of spiking rate and spiking history predicted discharge. PLoS Comput Biol 8: e1002681.

Devito LM, Eichenbaum H. 2011. Memory for the order of events in specific sequences: Contributions of the hippocampus and medial prefrontal cortex. J Neurosci 31: 3169-3175.

Diamond DM, Fleshner M, Ingersoll N, Rose GM. 1996. Psychological stress impairs spatial working memory: Relevance to electrophysiological studies of hippocampal function. Behav Neurosci 110: 661-672.

Dudchenko PA. 2004. An overview of the tasks used to test working memory in rodents. Neurosci Biobehav Rev 28: 699-709.

Dudchenko PA, Wood ER, Eichenbaum H. 2000. Neurotoxic hippocampal lesions have no effect on odor span and little effect on odor recognition memory but produce significant impairments on spatial span, recognition, and alternation. J Neurosci 20: 2964-2977.

Dudchenko PA, Talpos J, Young J, Baxter MG. 2012. Animal models of working memory: A review of tasks that might be used in screening drug treatments for the memory impairments found in schizophrenia. Neurosci Biobehav Rev doi: 10.1016/j.neubiorev.2012.03.003.

Floresco SB, Seamans JK, Phillips AG. 1997. Selective roles for hippocampal, prefrontal cortical, and ventral striatal circuits in radial-arm maze tasks with or without a delay. J Neurosci 17: 1880-1890.

Galizio M, Deal M, Hawkey A, April B. 2013. Working memory in the odor span task: Effects of chlordiazepoxide, dizocilpine (MK801), morphine, and scopolamine. Psychopharmacology (Berl) 225: 397-406.

Gold JM, Hahn B, Zhang WW, Robinson BM, Kappenman ES, Beck VM, Luck SJ. 2010. Reduced capacity but spared precision and maintenance of working memory representations in schizophrenia. Arch Gen Psychiatry 67: 570-577.

Goldman-Rakic PS. 1996. Regional and cellular fractionation of working memory. Proc Natl Acad Sci 93: 13473-13480.

Graybeal C, Feyder M, Schulman E, Saksida LM, Bussey TJ, Brigman JL, Holmes A. 2011. Paradoxical reversal learning enhancement by stress or prefrontal cortical damage: Rescue with BDNF. Nat Neurosci 14: $1507-1509$.

Holmes A, Wellman CL. 2009. Stress-induced prefrontal reorganization and executive dysfunction in rodents. Neurosci Biobehav Rev 33: $773-783$. 
Joels M, Baram TZ. 2009. The neuro-symphony of stress. Nat Rev Neurosci 10: $459-466$.

Kolb B. 1990. Animal models for human PFC-related disorders. Prog Brain Res 85: 501-519.

Koolhaas JM, Bartolomucci A, Buwalda B, de Boer SF, Flugge G, Korte SM, Meerlo P, Murison R, Olivier B, Palanza P, et al. 2011. Stress revisited: A critical evaluation of the stress concept. Neurosci Biobehav Rev 35: 1291-1301.

Lapish CC, Durstewitz D, Chandler LJ, Seamans JK. 2008. Successful choice behavior is associated with distinct and coherent network states in anterior cingulate cortex. Proc Natl Acad Sci 105: 11963-11968.

Leonard CJ, Kaiser ST, Robinson BM, Kappenman ES, Hahn B, Gold JM, Luck SJ. 2013. Toward the neural mechanisms of reduced working memory capacity in schizophrenia. Cereb Cortex 23: 1582-1592.

MacDougall MJ, Howland JG. 2012. Acute stress, but not corticosterone, disrupts short- and long-term synaptic plasticity in rat dorsal subiculum via glucocorticoid receptor activation. Cereb Cortex doi: $10.1093 /$ cercor/bhs 247.

MacQueen DA, Bullard L, Galizio M. 2011. Effects of dizocilpine (MK801) on olfactory span in rats. Neurobiol Learn Mem 95: 57-63.

Malkova NV, Yu CZ, Hsiao EY, Moore MJ, Patterson PH. 2012. Maternal immune activation yields offspring displaying mouse versions of the three core symptoms of autism. Brain Behav Immun 26: 607-616.

McFarland K, Kalivas PW. 2001. The circuitry mediating cocaine-induced reinstatement of drug-seeking behavior. I Neurosci 21: 8655-8663.

Nikaido Y, Nakashima T. 2011. Different patterns of neuronal activities in the infralimbic and prelimbic cortices and behavioral expression in response to two affective odors, 2,5-dihydro-2,4,5-trimethylthiazoline and a mixture of cis-3-hexenol and trans-2-hexenal, in the freely moving rat. Behav Brain Res 218: 218-227.
Paxinos G, Watson C. 1997. The rat brain in stereotaxic coordinates. Elsevier, Amsterdam.

Rushforth SL, Allison C, Wonnacott S, Shoaib M. 2010. Subtype-selective nicotinic agonists enhance olfactory working memory in normal rats: A novel use of the odour span task. Neurosci Lett 471: 114-118.

Rushforth SL, Steckler T, Shoaib M. 2011. Nicotine improves working memory span capacity in rats following sub-chronic ketamine exposure. Neuropsychopharmacology 36: 2774-2781.

Seamans JK, Floresco SB, Phillips AG. 1995. Functional differences between the prelimbic and anterior cingulate regions of the rat prefrontal cortex. Behav Neurosci 109: 1063-1073.

Seamans JK, Floresco SB, Phillips AG. 1998. D1 receptor modulation of hippocampal-prefrontal cortical circuits integrating spatial memory with executive functions in the rat. I Neurosci 18: 1613-1621.

St. Onge JR, Floresco SB. 2010. Prefrontal cortical contribution to risk-based decision making. Cereb Cortex 20: 1816-1828.

Thai CA, Zhang Y, Howland JG. 2013. Effects of acute restraint stress on set-shifting and reversal learning in male rats. Cogn Affect Behav Neurosci 13: $164-173$.

Witt RM, Galligan MM, Despinoy JR, Segal R. 2009. Olfactory behavioral testing in the adult mouse. J Vis Exp 23: 949.

Young JW, Kerr LE, Kelly JS, Marston HM, Spratt C, Finlayson K, Sharkey J. 2007. The odour span task: A novel paradigm for assessing working memory in mice. Neuropharmacology 52: 634-645.

Young JW, Powell SB, Risbrough V, Marston HM, Geyer MA. 2009. Using the MATRICS to guide development of a preclinical cognitive test battery for research in schizophrenia. Pharmacol Ther 122: 150-202.

Received June 25, 2013; accepted in revised form August 25, 2013. 


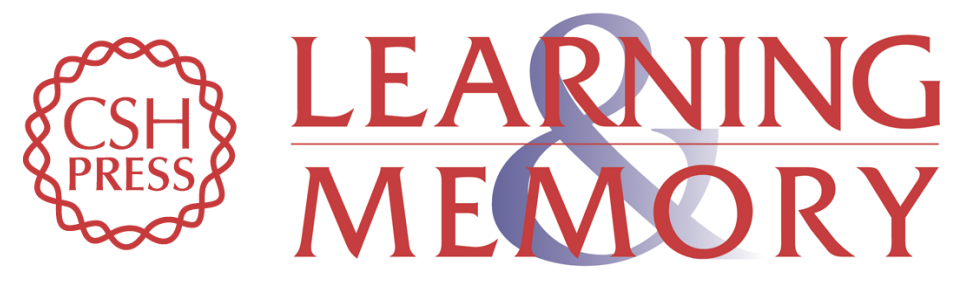

\section{Inactivation of medial prefrontal cortex or acute stress impairs odor span in rats}

Don A. Davies, Joel J. Molder, Quentin Greba, et al.

Learn. Mem. 2013, 20:

Access the most recent version at doi:10.1101/Im.032243.113

\begin{aligned} & \hline References $\begin{array}{l}\text { This article cites } 47 \text { articles, } 9 \text { of which can be accessed free at: } \\ \text { http://learnmem.cshlp.org/content/20/12/665.full.html\#ref-list-1 }\end{array} \\ & \begin{array}{r}\text { Creative } \\ \text { Commons } \\ \text { License }\end{array} \begin{array}{l}\text { This article is distributed exclusively by Cold Spring Harbor Laboratory Press for the } \\ \text { first } 12 \text { months after the full-issue publication date (see } \\ \text { http://learnmem.cshlp.org/site/misc/terms.xhtml). After } 12 \text { months, it is available under } \\ \text { a Creative Commons License (Attribution-NonCommercial } 3.0 \text { Unported), as } \\ \text { described at http://creativecommons.org/licenses/by-nc/3.0/. }\end{array} \\ & \begin{array}{c}\text { Receive free email alerts when new articles cite this article - sign up in the box at the } \\ \text { top right corner of the article or click here. }\end{array} \\ & \begin{array}{l}\text { Service } \\ \text { terting }\end{array}\end{aligned}$

